\title{
Medical-Education Strengthening By Inclusion Of Dental- Education Is An Utmost Necessity In INDIA \& World: A Perspective
}

\author{
Dr. D. K. Sharma \\ Additional Professor and Head Department of Anatomy All India Institute of Medical Sciences (AIIMS) \\ Raipur - 492099 - Chhattisgarh India
}

\begin{abstract}
In many countries, the present standing of the Dental-Education split from the Medical-Education is not good \& satisfactory towards providing healthcare to their citizens. It seems that it has evolved due to deficient knowledge for understanding the relation between oral diseases and general wellbeing \& systemic illnesses. It is an apparent truth that the dentistry is a part of Medical-Education/Profession and by its separation we have started an unnecessary race, competition \& gap between Dental and Medical to a large extent. The independent entity of dentistry from the rest of Medical-Education is a discrepancy and mysterious; and violating the ethics, equity \& justice of Medical-Education. Without careful exploring the ill effects and harms of dealing dental education separately from the Medical-Education by blindly following the other countries' model, is not justifiable; it is gratuitous and unnecessary in Indian reality \& socio-economic perspective. The integrity of Medical-Education/Profession with its various streams, including dentistry should be reconsidered and realized; and a prompt decision \& collective execution should be in use by the Government of India, Bioethicists, Medical-Educationists and Medical Council of India to merge BDS course into MBBS course, Dental colleges into Medical Colleges and Dental Council of India into Medical Council of India for maintaining the dignity and integrity of Medical-Education towards an excellent healthcare provision to Indian and people worldwide in a reasonable and affordable economic budget.
\end{abstract}

Keywords: Medical-Education, Dental-Education, Medical Council of India, Dental Council of India, Oral medicine, Discrimination

\section{Introduction}

The WHO (World Health Organization) conventional Medicine policy for 2014 to 2023 has been developed in response to the WHA (World Health Assembly) declaration on conventional medicine. The policy aimed to support affiliate states, for rising practical policies and executing action plans that will make stronger the role conventional medicine in keeping populations healthy. It devotes more attention to its forerunner to prioritising health facilities and systems together with conventional \& complementary medicine crop, practice and practitioner. Traditional medicine is knowledge, skill and practice based on the hypothesis, philosophy \& experience and original to different cultures. It is understandable or not, but used in the protection of health as well as in the avoidance, diagnosis and management of physical \& psychological illnesses.

Medical-Education is the education connected to the act of a medical-practitioner and it is teaching \& guidance to train a physician and surgeon. Medical-Education varies considerably across the world, in which different teaching \& guidance methods are utilised. Medical-Education is an active and broad area of enlightening research too in the field of medical science. Medical-Education courses are run at the medical school or institute or college. On the basis of jurisdiction and national law, these programs are either at an undergraduate level as in the largest part of Europe, India and China, or at a graduate level as in Canada, Australia and the United States. Preliminary Medical-Education is divided into the preclinical \& the paraclinical (including basic sciences like anatomy, physiology, biochemistry, pharmacology, and pathology) and the clinical (including medicine, pediatrics, obstetrics-gynecology, psychiatry, general practice, surgery) systembased integrated studies. All programs culminate in the graduate degree MD, MBBS, MBBCh, BM, etc. Some countries have implemented a proliferation of programs in which there is a combination of Medical-Education with research programs like $\mathrm{MD} / \mathrm{PhD}$ or with management programs MD/MBA but these were criticised because they extended interruptions in clinical study and they had a disadvantageous effect on the final clinical understanding in Medical-Education.

Graduated doctors undergo most often of one-year duration of supervised practice before full registration, which is referred to as an internship or residency-ship. In some countries the postgraduation or specialisation in a particular field of medicine commences immediately following completion of internship or residency ship, whereas in some other countries, before beginning specialisation requires junior doctors to undergo a general or an unstreamed training for a few months to a number of years. The CME (Continuing 
Medical Education) requirement varies from country to country for continued licensing or registration. Physicians and surgeons usually attend devoted lectures, imposing rounds, conventions and presentation improvement activities in order to complete requirements for continuing registration or licensing. In India, it is supervised by the MCI (Medical Council of India), similarly, in USA and Australia, the accreditation is supervised by the ACCME (Accreditation Council for Continuing Medical Education) and the AMC (Australian Medical Council) respectively.

Ever since I entered the medical field as an undergraduate student in my country, India, a question that has been plaguing my mind is why should there be a separate qualification (BDS), a separate college (Dental College) and a separate council (Dental Council of India) for a stream that deals with an organ of the human body the teeth only. Similarly, why don't we have individual qualifications, colleges and councils for the other streams \& organs of the body too? Why is this discrimination? I thought that as after completion of graduation MBBS, we do specialization / postgraduation MD/MS in different streams or parts of the body, then similarly why not similar MD/MS in dentistry too. If the dental problems/illnesses can be managed properly in the dentaldepartments of Medical Colleges then why Medical-Education should allow a separate DentalEducation/Profession in the form of BDS, Dental College \& DCI; and why should Dental-Education be dealt separately from Medical-Education? Is it not wastage of money, manpower and infrastructure of country to run a BDS course, the Dental Colleges and Dental Council of India under Dental-Education exclusively for the dentistry only when dental illnesses are manageable under MBBS/MD course, Medical College and MCI under Medical-Education? Is it not an unjustifiable and mysterious discrepancy violating the ethics, equity \& justice of Medical-Education?

The dentistry has been defined by WHO (World Health Organization) as "the science and skill which deals with preventing, diagnosing \& treating diseases, injuries $\&$ abnormalities of the jaws, teeth $\&$ mouth". During the middle Ages \& $19^{\text {th }}$ century the dentistry was not a self-determining education $\&$ profession in itself and often dental measures were executed by barbers or general doctors. The dentistry in all over the world is practiced in a different way and its teaching \& guidance varies as well from country to country.

The most important basic difference involves the relationship stuck between medicine and dentistry. Free-standing, profit-making dental colleges \& institutes for the UG (undergraduate) \& PG (postgraduate education) in dentistry in general \& specialized fields have become prevalent all over India. Though there is some convergence in many aspects but variations in views regarding dental education still persist, which cannot be denied. In a large sense, the derivation of Dental-Education has been found in the workings of the MiddleEastern \& Asian journalists who mentioned clarifications, images and instructions about an array of health troubles including oral illnesses.

With the revival of medical science in the west, some medical professionals experienced the oral health attractive, demanding \& challenging and dental illnesses \& services became further cut off from medicine. The best physicians \& surgeons could care or manage to the teeth of esteemed persons; princes, bishops and people at the high level of society, but in the past dental management in Europe turn out to be largely the preserve of barbers and quack general doctors. Occupational segregation was another factor contributed towards it. It was said that physicians more of a mind to support a sluggish and unbearable painful method of tooth removal or extraction, in compare to non-educated/untrained practitioners or non-physicians like barbers got work done very swiftly. In all probability it would have given confidence to people with this frequent problem to look for attention from untrained physicians or quacks and would have added to the division of dentistry from medicine.

During the $15^{\text {th }}$ century, progresses in the medical sciences highlighted the anatomical structure of the body, including the teeth \& neighbouring structures and Van Leeuwenhoek's recognition of microorganisms in tooth chafe. Scientist Fauchard in 1728 published his manuscript on the practice and comprehensive management in the field of dentistry. He is regarded as the father of modern dentistry and his publication became "a signpost" for the taking apart of dentistry on or after the regulation of surgery in medicine" [1].

In the nineteenth century, there happened a long-term discussion with reference to whether DentalEducation was paramount structured in a medical-institute or in self-determining school. On one side, some experienced that medical-schools are disinclined to provide substantial space \& exclusive apparatuses to hold up the scientific/mechanical guidance needed in dentistry and maintain truthfully mutually respectful relationships with dental-faculty, on the other side, some opinioned that as the dentistry is also outsized to be completed the extremities or closing stages of medical-practice, the bulk of the medical-institutes are not so happy in their standing as to propose encouragement for inward bound for relationships with the dentistry. The alternative view that dentists are not medical experts, they are a 'dump of carpenters' was also there.

In 1860, the recently framed ADA (American Dental Association) stimulated one of its working groups by placing an annual-statement on the situation of Dental-Education. Whether the self-governing approach was comparatively easier or not than amalgamation inside a medical-school, merely four dental-institutes were in set till 1865. Following appeals by the president of the Massachusetts Dental Society at Harvard in 1867, five more dental-schools were established till 1870 in affiliation with the medical-school. This group incorporated the 
initial university-based dental-curriculum. Twelve additional dental-schools were created in 1884, out of these nine with university based curriculum and three with self-supporting basis. Dozens of self-supporting proprietary (business-related) schools were instituted in the United States during the period between 1880 and 1890. New twenty eight dental-schools came into existence between 1883 and 1902 in Illinois only. On the other hand, African and American dentists had meetings as dental sections under the NMA (National Medical Association) as early as the 1890 s.

Europe showed a commencement of dental-education with more diversity. Several dental-schools were framed \& founded in Northern-Europe on the United State's model of autonomous schools, whereas in Southern-Europe Dental-Education developed as a discipline in a medical-school and alumnae obtained medical-degrees. After a result of alteration during 1980s stimulated in part by directions of the EEC (European Economic Community), it is single Austria, which at the standstill associations' dental-licensure to a medicaldegree.

The earliest short-term dental-hygiene-school founded in 1910 and marked off one group of students ahead of confined dentists; achieved something in finishing it then a second program in 1913 as the Fones School of Dental-Hygiene formed at Connecticut in Bridgeport. In 1923, the ADHA (American Dental Hygienists Association) and AADS (American Association of Dental Schools) were founded. In the year 1947, ADHA and ADA laid down the first authorization standard for dental-hygiene plans and at present these plans an array in extent from two to four years with an associate or a baccalaureate degree. The Carnegie institution for the improvement of teaching \& training financed a chain of information on specialized teaching \& training in the United States of America. The study of Abraham Flexner in 1910 on Medical-Education was a landmark occurrence in the journal of the $4^{\text {th }}$ report and even today; this report still outlines the medical and dental disciplines' courses. This report paid attention on numerous themes and novelties in Medical-Education together with the drafting in opposition to commercial medical-institutes, validation of the connection between universities \& professional institutes, formation of higher standards for medical-institute admittance \& competent around the clock faculties and movement in the direction of education stuck in precise controlled investigations \& opinions.

Professor Biochemistry, William Gies had commented that dentistry should be fittingly considered as the oral area of expertise of medicine. Scientific opinions and helps can put in order dental-students to be the scholar examinees and contemporaries of medical-students. William Gies and the head of the Carnegie institution as well recommended that the medical-students be improved and trained in the oral-health at medicalinstitutes. The core curriculum could still be prolonged to attain superior connection with experimental medicine in medical science. Dentistry can be intimately associated educationally with medical curriculum and Government should efficient endeavor to direct their alumnae into populations during require of dental service as well. It is deniable that dental-institutes have become more or less equivalent to those of Medical-Institutes. Private institutions have participated and persist to engage in recreation in encouraging significant thoughts and collation of Dental \& Medical-Education. The government should initiate an alert even though still unpretentious try to uphold research in oral-health and troubles. It is imperative to combine dental into MedicalEducation in a field to act together in favour of excellence and merit in the field of public healthcare.

In addition to the incongruity about the process and material of official approval \& license, the debate between educationalists and government should be distinguished towards the combined effort in medicine. Controversy has focused on the dental institute, which motivated the resistance of physicians from their most primitive days. To improve health services in underserved areas and underdeveloped areas with shortages of health personnel, the focus by the government is necessary for partially or completely support financial care to those who could not meet the expense to pay for their cure. In the majority of cases, neighboring medical \& dental people in fused form as well as the local administration should be in agreement for the terms of dearth areas. Usually unfriendliness by the dental assemblies was in fact, more frequent than medical groups. The report of the Higher-Education as well as the Nation's Health had prevalent synchronization that the country had a scarcity of doctors, surgeons, \& health experts which pushed growth in the number of health professionals and educational-supported training of doctors \& the surgeon's assistants and also the wished-for establishment of an improved nation's health program.

The First Dental-college was established in Kolkata India in 1924, devoid of government aid, by Dr. Rafiuddin Ahmed and it was named as Calcutta Dental College and Hospital. Surprisingly, it was recognized as the first Dental-college in Asia. In 1965 after the death of Dr. Ahmed the college was renamed on his name. The next Dental-college came in to power in 1933 in Mumbai with the name as Nair Hospital and Dental College and run by the Municipal Corporation of Greater Mumbai. Surprisingly it was distinguished as the only dental college in the world running by a municipal authority. Then in 1935, Dr. H. Venkata Rao instituted a Dentalcollege in Chennai with the name "Madras Dental College \& Hospital" but it underwent failure up in 1942. The Government of India in 1943 set up a community health-survey by a commission lead by Sir Joseph Bhore for getting proposals for enhancing health-services in India. This commission suggested the improvement of dental- 
services and starting of dental-colleges. Then in 1946, the IDA (Indian Dental Association) came into the force which decorated the inevitability for regulating the dental-practice in the nation. Finally there existed the enactment of the dentist's act 1948 and frame of DCI (Dental Council of India) in 1949 at the central \& state levels. Also in December 1949, the government structured \& approved the starting of a separate Dental-wing connected to Madras Medical-College and Government General-Hospital Madras to guide entrants for the BDS course and suggested an entry of fifteen students every year from the year 1953. The government also ordered for the disconnection of Dental-wing from the Madras Medical College and establishment of an independent Madras Dental College with independent funds from 3rd October 1979. This Madras Dental College was inaugurated by the Governor of Tamilnadu Shri Prabhudas Patwari on February $26^{\text {th }}, 1980$. In this division, the Dean of Madras Medical College withdrew the charge and Dr. B. P. Rajan was appointed as Principal of Dental College. The institution was renamed as Tamilnadu Government Dental College and Hospital in 1992 and affiliated to Dr. MGR Medical University, Chennai, since the commencement of Medical University.

The DCI was formed as a statutory body by Parliament on 12th April 1949 under the Dentist Act-1948 (XVI) with a vision to standardize the Dental-Education, profession \& ethics; and it approached into subsistence in the March 1949. On 27th August 1992, the President of India made the amendments in the course of a regulation or circulation and through which set up the new sections 10A, 10B, \& 10C under Dentists Act-1948 chiefly to control the escalating number of dental colleges, raising the seats in courses and opening of newfangled superior courses with no former consent of the Ministry of Health \& Family Welfare, Government of India. The DCI is funded mainly by the Ministry of Health \& Family Government of India, but in addition the other source of revenue is the $1 / 4^{\text {th }}$ share of fees grasp yearly by the different State Dental Councils underneath the section-53, inspection fee by the dental-institutes under section 15 , application fee by the dental-institutes to commence \& also to start of higher courses \& increase of admission seats under section 10A of Dentists Act1948 according to an amendment in the Dentists Act-1993.

The IOM (Institute of Medicine) Japan in 1995 presented its report as Dental-Education on the moment of truth or turning point: Confront and Transform. The IOM was asked for more rapidly "nearer incorporation" of the dentistry in medicine, with the "most important" likelihood being dentistry appropriately incorporated with medicine as an area of expertise or field of medicine. In Japan, the moment in time has appeared for Dental-Education to merge structurally \& functionally in the Medical-Education [2].

\section{Discussion}

In many countries, the present autonomous situation of Dental-Education detached from the MedicalEducation is not fine \& reasonable for the teaching and training of an oral physician or surgeon towards providing healthcare to citizens. Perhaps, Modern Dental-Education commenced in the 19th century as a selfdetermining specialized curriculum divergent from medicine for the reason of the overpowering pervasiveness \& rigorousness of dental illnesses. It seems, during that time it had been solely managed by mechanical treatments. Possibly it evolved autonomously also due to deficient knowledge regarding the relationship between oral illnesses \& general health as well as systemic diseases. In the $21^{\text {st }}$ century, the training of oral physicians and surgeon with a crucial Medical teaching \& training is the most suitable approach to build up potential dentists under Medical-Education. A fresh report from the Institute of Medicine give emphasis to the requirement for changes in Dental-Education to get ready for an upcoming that will in many significant ways is quite unlike from the past [3].

So it is the author's personal perception that in India it was a mistake or error to separate the dentalwing from the medical-college or hospital and giving the dentistry as an independent entity from MedicalEducation. It definitely happened like cutting a part of the human body and giving \& dealing that part with an independent name and identity unnecessarily. In this manner that cut part and rest of the body both lost their beauty and perfection structurally \& functionally. The Medical-Education/Profession can be compared to be like a hand and dentistry is it's one of the digits; and on separation of any digit from the hand, there is removal of beauty $\&$ function of both and there is a loss of strength of fist too.

In the country like India, the presence of gaping holes \& deficiencies in the policies $\&$ programs are usual happening and not deniable. It is also understandable truth that not deleting or amending the wrong trends \& errors seriously leads to the failure of obtaining significant achievements to the expectations in the field like public healthcare under Medical-Education. It is an apparent truth that the dentistry is a part of MedicalEducation/Profession and by its separation we have started an unnecessary race, competition \& gap between Dental and Medical to a large extent. This starting separate entity of dentistry was a mistake which has been reflected and resulted as obtaining expensive dental care by the general public of our country. The independent entity of dentistry from the rest of medical education is a discrepancy and mysterious; and violating the ethics, equity \& justice of Medical-Education. Without careful exploring the ill effects and harms of dealing dental education separately from Medical-Education by following other countries' model blindly is not justifiable; it is gratuitous and unnecessary in Indian reality \& socio-economic perspective. 


\section{Conclusion}

The integrity of Medical-Education/Profession with its various streams, including dentistry should be reconsidered and realized; and a prompt decision \& combined efforts should be in use by the Government of India, Bioethicists, Medical-Educationists and MCI to merge BDS into MBBS, Dental-colleges into MedicalColleges and DCI into MCI for maintaining the dignity and integrity of Medical-Education towards an excellent healthcare provision to Indian and people worldwide in a reasonable and affordable economic budget. It is thus advisable that dentistry should be one area of expertise of Medical-Education to be designated as ORAL MEDICINE to produce oral physicians/surgeons under Medical-Education. The joint understanding \& close collaboration of medical \& dental experts \& educationists are the utmost necessity and of vital importance for the flourishing \& a victorious founding of an incorporated program for excellent human healthcare and also for strengthening the Medical-Education in India to achieve its objectives \& goals conveniently towards the welfare of the country. At the end I have no hesitation in appealing strongly to everyone that including dentistry in Medical-Education is an utmost necessity towards excellent healthcare provision in INDIA.

Ethical Guidelines, Permission and Approval: The manuscript is a perspective of only author towards Medical-Education strengthening, it is following the ethical guidelines and no any permission or approval was required.

\section{References}

[1]. Banoczy J, Rigo O, Albrecht M. Prevalence study of tongue lesions in a Hungarian population Community. Dent Oral Epidemiol. 1993 Aug; 21(4):224-6.

[2]. Kenzo Tanaka, Takeshi Honda and Kenji Kitamura. Dentistry in Japan Should Become a Specialty of Medicine with Dentists Educated as Oral Physicians. Journal of Dental Education. 2008 September; 72(9):1077-83.

[3]. Field MJ, Jeffcoat MK. Dental education at the crossroads: a report by the Institute of Medicine. J Am Dent Assoc. 1995 Feb; 126(2):191-5. 